\title{
Prognostic value of preoperative myocardial fibrosis assessment by delayed enhancement cardiac magnetic resonance imaging in patients undergoing mitral valve repair
}

Kongkiat Chaikriangkrai ${ }^{* *}$, Juan C Lopez-Mattei ${ }^{2}$, Homam Ibrahim² ${ }^{2}$, Stephen H Little², William Zoghbi Miguel A Quinones², Gerald Lawrie², Dipan J Shah²

From 17th Annual SCMR Scientific Sessions

New Orleans, LA, USA. 16-19 January 2014

\section{Background}

Cardiac MRI has been shown to be the gold standard for noninvasive assessment of myocardial fibrosis. The extent of fibrosis has been associated with worse outcomes in patients undergoing CABG surgery. The presence of fibrosis and associated clinical features of patients with chronic mitral regurgitation undergoing mitral valve repair have not been described. The objective of this study is to examine prognostic value of preoperative myocardial fibrosis assessment by cardiac MRI in patients with chronic mitral regurgitation undergoing mitral valve repair.

Table 1 Baseline clinical and cardiac MRI characteristics categorized by presence of myocardial fibrosis

\begin{tabular}{|c|c|c|c|c|}
\hline Variables & $\begin{array}{l}\text { All patients } \\
(\mathrm{N}=48)\end{array}$ & $\begin{array}{l}\text { NO fibrosis } \\
(\mathrm{N}=29)\end{array}$ & $\begin{array}{l}\text { WITH fibrosis } \\
\quad(\mathrm{N}=19)\end{array}$ & $\mathbf{P}$ \\
\hline Age, years (SD) & $61(13)$ & $59(11)$ & $65(15)$ & 0.112 \\
\hline Male sex, No. (\%) & $33(69)$ & $18(62.1)$ & $15(78.9)$ & 0.217 \\
\hline $\mathrm{BMl}, \mathrm{kg} / \mathrm{m} 2$ (range) & $28.4(19.0-56.1)$ & $27.0(19.0-56.1)$ & $29.4(19.5-53.5)$ & 0.348 \\
\hline Functional mitral regurgitation, No. (\%) & $13(27.1)$ & $5(17.2)$ & $8(42.1)$ & 0.06 \\
\hline History of diabetes mellitus, No. (\%) & $7(14.6)$ & $3(10.3)$ & $4(21.1)$ & 0.31 \\
\hline History of dyslipidemia, No. (\%) & $23(47.9)$ & $11(37.9)$ & $12(63.2)$ & 0.09 \\
\hline History of hypertension, No. (\%) & $30(62.5)$ & $16(55.2)$ & $14(73.7)$ & 0.20 \\
\hline Hemoglobin level on admission, g/dL (range) & $13(7-16)$ & $13.0(8.0-15.0)$ & $13.0(7.0-16.0)$ & 0.574 \\
\hline Statins, No. (\%) & $14(29.2)$ & $6(20.7)$ & $8(42.1)$ & 0.110 \\
\hline ACEI or ARB, No. (\%) & 19 (39.6) & $8(27.6)$ & $11(57.9)$ & 0.036 \\
\hline$\beta$ blockers, No. (\%) & $25(52.1)$ & $12(41.4)$ & $13(68.4)$ & 0.067 \\
\hline Aspirin, No. (\%) & $22(45.8)$ & $13(44.8)$ & $9(47.4)$ & 0.863 \\
\hline Cardiac MRI LVEF, \% (SD) & $63.04(11.86)$ & $63.31(12.34)$ & $62.63(11.40)$ & 0.85 \\
\hline Cardiac MRI RVEF, \% (SD) & $52.00(10.33)$ & $52.97(10.62)$ & $48.84(9.60)$ & 0.18 \\
\hline Cardiac MRI LVEDV, mL (SD) & $200.00(61.34)$ & $199.42(57.56)$ & $198.34(68.33)$ & 0.95 \\
\hline Cardiac MRI LVESV, mL (SD) & $68.50(41.03)$ & $75.63(40.25)$ & $76.50(43.31)$ & 0.94 \\
\hline
\end{tabular}

${ }^{1}$ Medicine, The Methodist Hospital, Houston, Texas, USA

Full list of author information is available at the end of the article 
Table 2 Postoperative clinical outcomes categorized by presence of myocardial fibrosis

\begin{tabular}{ccccc}
\hline Clinical outcomes & $\begin{array}{c}\text { All patients } \\
(\mathbf{N}=\mathbf{4 8})\end{array}$ & $\begin{array}{c}\text { No fibrosis } \\
(\mathbf{N}=\mathbf{2 9})\end{array}$ & $\begin{array}{c}\text { WITH fibrosis } \\
(\mathbf{N}=\mathbf{1 9})\end{array}$ & $\begin{array}{c}\mathbf{P} \\
\text { Significant arrhythmia*, No. }(\%)\end{array}$ \\
\hline Cardiac pacing, No. (\%) & $24(50.0)$ & $10(34.5)$ & $14(73.7)$ & 0.008 \\
\hline ICU readmission or significant arrhythmia or cardiac pacing & $20(41.7)$ & $7(24.1)$ & $13(68.4)$ & 0.002 \\
\hline
\end{tabular}

* Atrial fibrillation, sinus bradycardia requiring cardiac pacing, AV blocks requiring cardiac pacing

\section{Methods}

This is a prospectively enrolled consecutive series of 48 subjects with chronic mitral regurgitation who underwent cardiac MRI followed by mitral valve repair using the nonresectional dynamic technique from August 2008 - April 2013. Pre-operative fibrosis burden, other cardiac MRI and clinical variables were collected. Differences among variables between subjects with and without fibrosis were statistically calculated.

\section{Results}

The cohort had a mean (SD) age of 61(13) years and included 33 men (69\%). Median postoperative follow up interval was 53.5 days (Interquartile range 10 and 442 days). Mean (SD) interval between cardiac MRI and mitral valve repair was 19.58 (18.37) days. Fibrosis was present in 19 subjects $(39.6 \%)$ with a median fibrosis burden of $4 \%$ of the left ventricle. Within the fibrosis group, 9 (47.4\%) had a non-coronary artery disease fibrosis pattern. Comparison of selected baseline clinical and cardiac MRI variables is shown in the Table 1. Postoperative clinical outcomes are shown in the Table 2. In multivariable analysis, presence of preoperative fibrosis is an independent predictor for postoperative cardiac pacing (OR 7.652; 95\%CI 1.636, 35.783, p0.010), postoperative significant arrhythmia (OR 4.403; 95\%CI $0.997,19.443$, p0.050) and a composite of ICU readmission/postoperative significant arrhythmia/postoperative cardiac pacing (OR 5.057; 95\%CI 1.130, 22.622, p0.034).

\section{Conclusions}

Presence of preoperative myocardial fibrosis derived from cardiac MRI is associated with worse postoperative outcomes in patients with chronic mitral regurgitation undergoing mitral valve repair.

\section{Funding}

None.

\footnotetext{
Authors' details

${ }^{1}$ Medicine, The Methodist Hospital, Houston, Texas, USA. ${ }^{2}$ Methodist DeBakey Heart \& Vascular Center, The Methodist Hospital, Houston, Texas, USA.

${ }^{3}$ Cardiothoracic surgery, The Methodist Hospital, Houston, Texas, USA.
}

doi:10.1186/1532-429X-16-S1-P284

Cite this article as: Chaikriangkrai et al:: Prognostic value of preoperative myocardial fibrosis assessment by delayed enhancement cardiac magnetic resonance imaging in patients undergoing mitral valve repair. Journal of Cardiovascular Magnetic Resonance 2014 16(Suppl 1):P284.
Submit your next manuscript to BioMed Central and take full advantage of:

- Convenient online submission

- Thorough peer review

- No space constraints or color figure charges

- Immediate publication on acceptance

- Inclusion in PubMed, CAS, Scopus and Google Scholar

- Research which is freely available for redistribution

Submit your manuscript at www.biomedcentral.com/submit 